\title{
Identification, Measurement and Reflection of Risks in Accounting
}

\author{
Natalia Chebanova ${ }^{11}$ Victoria Orlova $^{1}$, Liliy Revutska ${ }^{1}$, and M. Karpushenko ${ }^{2}$ \\ ${ }^{1}$ Ukrainian State University of Railway Transport, Economy and Management of Industrial and \\ Commerce Business Department, Feuerbach sq. 7, 61050 Kharkiv, Ukraine \\ ${ }^{2}$ O.M.Beketow National University of Urban Economy in Kharkiv
}

\begin{abstract}
In the modern environment, the company constantly faces various types of risks in its business activities. Therefore, the problem of identifying and measuring risks is extremely relevant. The article proposes a scheme for managing financial risks, which includes identifying risk factors, determining the permissible risk level, analyzing individual transactions, developing risk mitigation measures. The article proposes to create the following funds, reserves and collateral: a bad debts reserve, provision for warranty service of clients, provision for social orientation, provision for restructuring, provision for burdensome contracts, fiscal (tax) reserves, commercial, industrial, informational risk reserves, future costs and payments reserve, legal provisions, provisions for impairment of assets, reserve fund. Risks should be taken only if the level of return on risky operations exceeds the level of risk. The issue of the choice of certain reserves, funds and provisions is regulated by the accounting policy of the enterprise, where their types and the order of their creation should be clearly defined. Such measures allow planning contingency expenses and informing users of financial statements of future risk events.
\end{abstract}

\section{Introduction}

The issue of identification and measurement of business risks is extremely important for modern business, as under all circumstances a situation can occur that will negatively affect the company and lead to unexpected financial consequences. All this requires the establishment of an effective risk management system that would identify, predict, and measure risks. It should be emphasized that it is accounting where there are certain rules and standards allowing pre-evaluating of the business risks. Therefore, accounting norms and principles of risk management should be combined to create such a system.

Business risks were analyzed in works by C. Drury [1], P. Atamas [2], L. Gnilitska [3], I. Deroun [4], I. Chibisova [5], B. Zasadny [6] and other scientists.

Having analyzed the study of risks, we can conclude that there is no single concept of risk management, since this problem has been considered from various aspects. For instance, I. Deroun [4] focused on approaches to understanding risks and developed a set of indicators to identify risks in the accounting system. L. Gnilitska [3] separated the risk-causation and risk-consequence and proposed a generalizing scale for assessing the probable consequences of the business risk, and analyzed the effect of risk on the value of

\footnotetext{
${ }^{1}$ Corresponding author: $\underline{n \text { chebanova@ukr.net }}$
} 
accounting objects. Some scientists, namely P. Atamas [2], I. Chibisova [4] and others, focused on risk management. However, some important issues related to risk measurement and forecasting remain unclear and not sufficiently specified.

The concept of "risk" is considered by most researchers as the possibility of occurrence at an enterprise, which can cause loss of property, funds, expected profit deficiency, income, the introduction of additional costs as a result of adverse circumstances or events. But there is another interpretation. Thus, according to B. Zasadniy [5], "risk" should be interpreted as a combination of phenomena, events and factors that influence the making managerial decisions and can lead to both positive and negative result of the enterprise. According to C. Druri [1], if there are more than one possible outcomes, we can speak about risk. I.e., the "risk" is associated with an unexpected event - either negative or positive. In our opinion, the risk of business activity is associated with unexpected or anticipated future events that are likely to lead to expenditures. The risk may be caused by various factors that are related both to the internal circumstances associated with the production, financial and commercial activities of the enterprise, and with external factors such as inflation, political and economic situation, exchange rate changes, demographic situation, etc.

\section{Presentation of the main results}

The most common type of risk is financial risk, which can include the risk of insolvency, crime risk, loan risk, risk of financial stability, risk of inflation, tax risk, currency risk, deposit risk, investment risk, and others. In addition to the traditional types of risks that are already known for a sufficient amount of time, the use of IT technologies has brought new types of risks - risks associated with cyber attacks, viruses, Internet fraud, loss of reputation due to negative information and other risks. Information risks present the most serious threat to any enterprise today, especially if this company is actively working on the Internet. But of course, each enterprise has its own types of risks associated with the specifics of their activities.

The result of the occurrence of risk events - the losses that can be estimated in cash.

Recently, the influence of the accounting system on the adoption of managerial decisions and the assessment of any events is increasing. An enterprise should strive to reflect in the financial statements not only information about risks, but also about their impact on the financial position of the enterprise and the size of possible losses. The concept of risk is associated with the expectation of any events, business operations, the cost of which is not predetermined. You can identify many types of risks, but surely all risks should not be displayed. In order to confirm this position, it is necessary to refer to accounting norms.

The concept of materiality in the financial statements is determined by IAS 1 "Presentation of Financial Statements" [7].According to the standard, significant omissions or errors occur when they can, individually or collectively, affect the economic decisions taken by users on the basis of their financial statements. The boundary between significant events is determined by the specific value that each enterprise determines, depending on the size of the assets, income or profit in the accounting policy. Thus, it is necessary to compare the costs associated with risk events, with the limit of materiality. If these costs do not exceed the limit, they should not be displayed if their expected size is greater - they should be reflected to provide accurate reporting. An important role is played not only by the size of costs but also by the probability of a risk event occurring. For example, according to L. Gnilitska [3], it is expedient to reflect only such events, the probability of occurrence of which exceeds $50 \%$. And unforeseen obligations that have a small probability of manifestation (10-50\%), it is expedient to display off-balance sheet for further control of their offensive. Contingent liabilities, characterized by a minimal probability of their occurrence $(0-10 \%)$, should be considered a real uncertainty, which is not reflected in the balance sheet. 
Based on the fact that the risk is due to negative so positive events, they should be taken if the level of return on risky operations will exceed the size of expected costs. At the same time, the company's expenses for the neutralization of risk should not exceed the amount of losses on it. According to I. Chibisova [4], risk management is based on the application of the principles of risk-taking. P. Atamas [2] states that enterprise risk management involves substantiation of leading tasks and methods of risk neutralization, among which there are two main types of strategies: passive and active. Choosing a passive strategy, the company carries out risk avoidance operations, that is, it refuses or reduces its risk operations. Active strategy is aimed at carrying out risky operations, but commercial insurance and selfinsurance of risks, their diversification and hedging prevent their negative impact from being reduced.

It is expedient to structure the process of risk management as a sequence of certain stages (fig. 1):

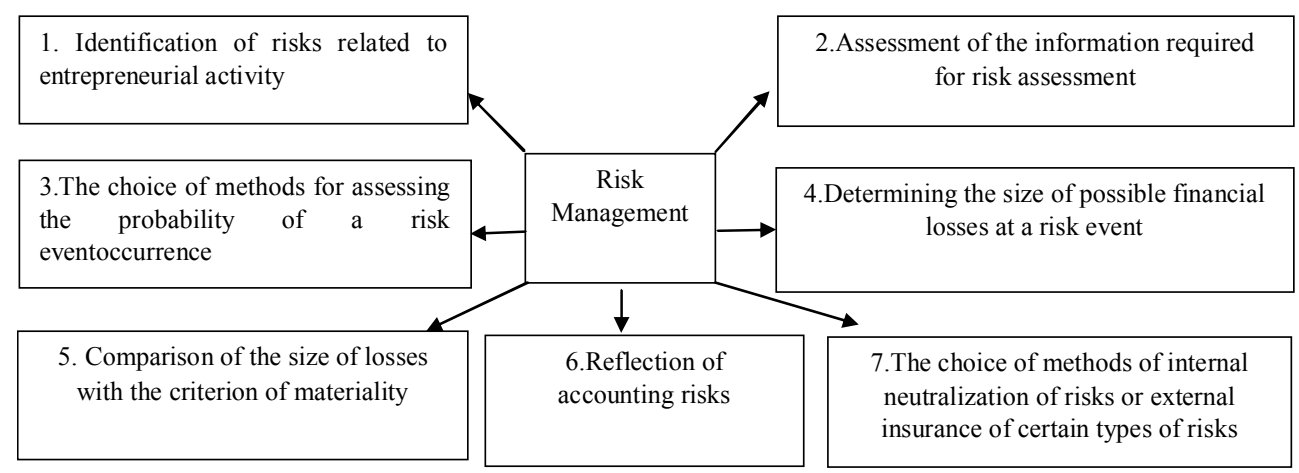

Fig. 1. Risk Management Process.

The most difficult step is to determine the scope of possible losses on risky events. To do this, you need to choose a particular method of evaluation. In practice, the following methods are most commonly used to assess risks:

- expert-based on a group of experts' survey, with further processing of the results of this survey;

- statistical - apply in the presence of statistical data for a number of previous periods;

- computational analytical - designed to calculate the precise quantitative expression of the level of risk based on the internal information of the enterprise itself;

- analogue - allow you to assess the level of risk in individual transactions based on comparison with similar, already multiple operations. In order to ensure the reliability of the comparison, both their own and external experience of such operations are used.

The use of a method depends on the specific conditions and types of risk. The choice of any of the methods is related to solving the question of the adequacy and reliability of the information that is present in the enterprise.

From the point of view of the possibility of influence and application of assessment methods, the following types of risk can be distinguished (Figure 2): 


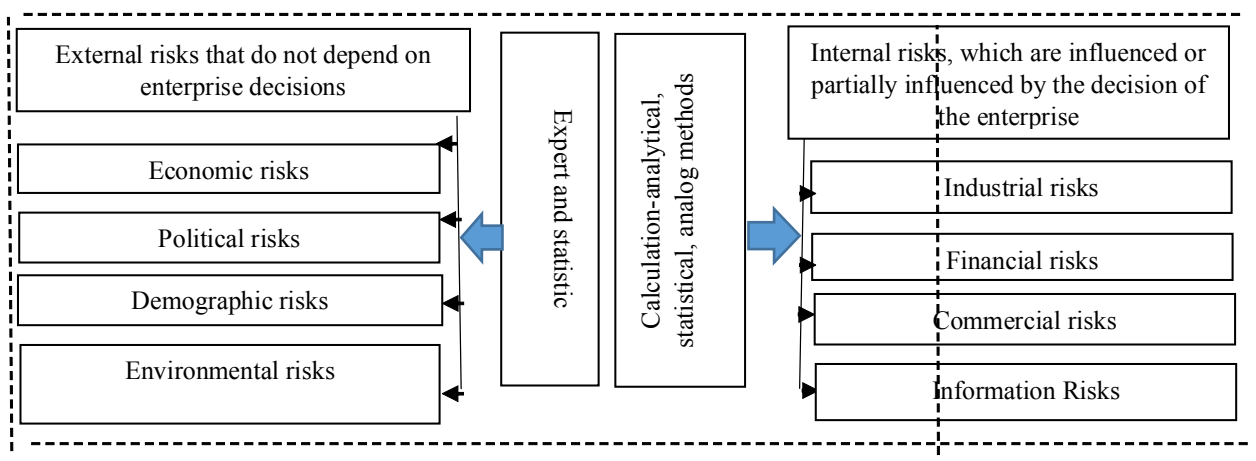

Fig. 2. Application of assessment methods for various types of risk.

Having determined the probable amount of losses from risk events and making sure that it is really significant and may affect the decision of the owners of the company, it must be reflected in the accounting. This can be done by one of the following approaches:

1) the creation of certain reserves, provisions, funds - the application of such an approach will lead to the enterprise recognizing in advance the costs that will be incurred if the risk event occurs. If there is a need for this, you can defer these funds to a deposit account and then use them in case if such an event will occur in the future;

2) reflection in the notes to the financial statements - the enterprise records the existing risk events that may affect the company and lead to significant changes in the financial statements.

Indeed, in accordance with IAS 1, "Presentation of Financial Statements" [7], the notes disclose non-financial information, in particular the sources of estimation uncertainty at the end of the reporting period that present a significant risk and may lead to a significant adjustment of the balance cost of assets and liabilities for the following fiscal year. In respect of such assets and liabilities, notes should contain detailed information about their nature and their balance cost at the end of the reporting period. It should be emphasized that all features of the creation of reserves, funds and provisions should be reflected in the accounting policies of the enterprise.

To create reserves, collateral and funds, it is the most optimal to use the computational and analytical methods, which are based on the indicators of a particular enterprise and take into account the norms of accounting standards.

Let's consider the features of creating reserves, collateral and funds. If we take into account the generalities of calculating the cost of risk events, it is advisable to classify them into three groups.

The first group is the reserves, funds and collateral that can be calculated on the basis of accounting data of previous periods with the use of calculation and analytical methods. This group includes the following reserves and collateral (Fig. 3): 


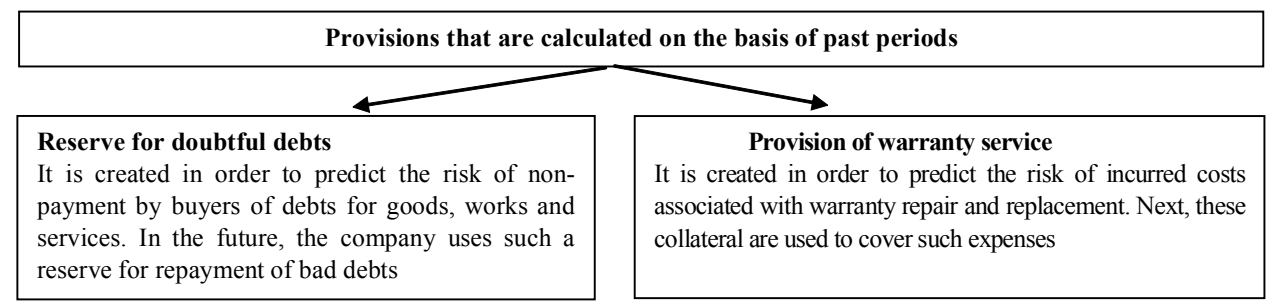

Fig. 3. Types of provisions that are calculated based on past periods.

To calculate these reserves, the accounting data of previous periods is used. I.e, it is assumed that the amount of expenses which the enterprise had in the event of a risk event in past periods will be approximately equal to the amount of costs in future periods. The more periods taken into account, the more accurate the results of the calculations. For example, to calculate the warranty service provision, it is necessary to gather information on the amount of costs actually incurred by the company in connection with the performance of warranty substitutes. For this purpose the following formula can be used:

$$
S_{r i}=R_{i} x\left(\left(\sum E_{n} / R_{n}\right) / n\right)
$$

$S_{r i}$ provision of warranty service of the i-th period;

$\mathrm{R}_{\mathrm{i}}$ - revenues of the $\mathrm{i}$-th period;

$E_{n^{-}}$- expenses for warranty service of past periods;

$R_{n}$ - revenues of past periods

$n$ - the number of previous periods.

The second group is the reserves, funds, provisions, which are based on reliable information of the company about future costs. This information can be estimated on the basis of available documents-calculations, estimates, accounts, etc. (Fig. 4).

\begin{tabular}{|c|c|c|c|c|c|}
\hline \multicolumn{6}{|c|}{ Provisions that are calculated based on available estimates of future costs } \\
\hline & & & & & \\
\hline 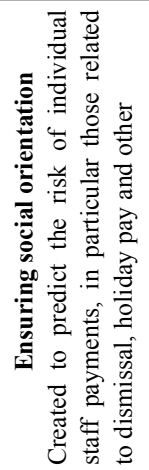 & 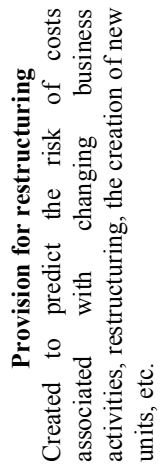 & 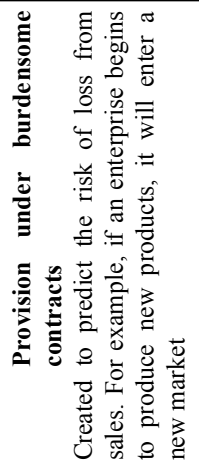 & 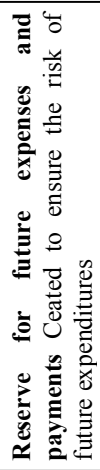 & 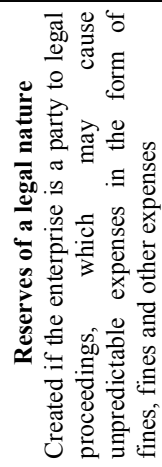 & 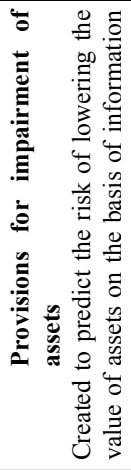 \\
\hline
\end{tabular}

Fig. 4. Types of provisions that are calculated on the basis of future periods. 
To determine the size of the cost of risk events for the given group evaluated certain documents, on the basis of which are made calculations. For example, in order to calculate employee benefits, information is required on the size of the wage bill and the amount of holiday pay planned for the year as well as the actual wage bill for the current period.

But there is such a provision, the size of which is not calculated, but is based on the data contained in the estimates, calculations and other documents. This, for example, is a provision for restructurings, a reserve for future payments and payments, etc. (Fig. 5):

\begin{tabular}{|l|l|l|}
\hline \multicolumn{1}{|c|}{ Reserves which are calculated on the basis of expert assessments } \\
\hline $\begin{array}{l}\text { It is created for insurance } \\
\text { of the enterprise from any } \\
\text { unforeseen circumstances }\end{array}$ & $\begin{array}{l}\text { Reserves for indemnification of commercial, } \\
\text { industrial, informational risks } \\
\text { For prediction of production, property risks, risks } \\
\text { of implementation process, information risks, } \\
\text { insufficient and untimely development }\end{array}$ & $\begin{array}{l}\text { Fiscal (tax) reserves } \\
\text { For company insurance in case } \\
\text { of payment of unforeseen } \\
\text { taxes, fines }\end{array}$ \\
\hline
\end{tabular}

Fig. 5. Types of reserves that are calculated on the basis of expert assessments.

Indeed, the specified reserves can not be assessed based on past periods or available documents. For example, a reserve fund is formed from a net profit of an enterprise, the decision on its size is taken by the owner of the enterprise, taking into account a number of features of the operation of the enterprise.

Determining such reserves (provisions, funds) is a problem that should be solved by experts, the owner, the chief accountant, the financial director, the head of the company and other specialists, taking into account the events of future periods.

\section{Conclusions}

The problem of identification, measurement and risk assessment is extremely relevant, since today, enterprises may have situations that involve risks. Risk management is a rather complicated process that depends on its types and involves a procedure for certain actions and the application of methods for assessing possible losses. Particular attention is paid to accounting methods of risk insurance. These methods include the creation of reserves and provisions, certain funds that will be used in future to offset potential losses. Establishing reserves, funds, provisions for each enterprise is regulated in the accounting policy of the enterprise, where their types and procedure of creation should be clearly defined.

\section{References}

1. Druri, C. Management and cost accounting. Moscow: Uniti-Dana, (2005)

2. Atamas, P.J., Atamas, O.P., Kramarenko, G.O. Academic review, 1 (44), 60-69, (2016)

3. Gnilitska, L. V. Economic innovation, 57, 88-100, (2014)

4. Derun, I.A. Economic Annals-XXI, 159(5-6), 97-100, (2016)

5. Chibisova, I.V., Levchyn B.V. The problems of e systemic approach in economic, 2(56), 113-116, (2016)

6. Zasadnyi, B. A. Nay Scientific herald of Uzhgorod National University, 14 (1), P. 111 115, (2017)

7. IAS 1 "Presentation of Financial Statements"- URL: https://www.ifrs.org/issuedstandards/list-of-standards/ias-1-presentation-of-financial-statements/ 